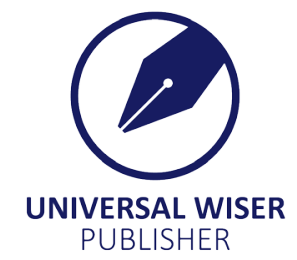

\title{
An Experimental Study PVDF and PSF Hollow Fiber Membranes for Chemical Absorption Carbon Dioxide
}

\author{
Ehsan Kianfar \\ Department of Chemical Engineering, Arak Branch, Islamic Azad University, Arak, Iran \\ Young Researchers and Elite Club, Gachsaran Branch, Islamic Azad University, Gachsaran, Iran \\ Email: ehsan_kianfar2010@yahoo.com, e-kianfar94@iau-arak.ac.ir
}

\begin{abstract}
Poly (vinylidene fluoride) (PVDF) and poly-sulfone (PSF) polymer solutions were made at a concentration of $18 \%$ by weight of the polymer as a non-soluble additive of polymer solution in 1-methyl-2-pyrrolidone (NMP) solvent. PVDF and PSF hollow fiber membranes were fabricated via the wet phase-inversion process. Fabricated membranes were characterized in terms of gas permeability, wetting resistance, water contact angle and overall porosity. In order to study the structure of the membranes made, the scanning electron microscopy images of the model (TM3000, HITACHI, Japan) were used. The morphology study indicates that the PSF membrane shows an open cross-section structure with smaller pore sizes. However, the PVDF membrane illustrates a thick sponge-like structure. The fabricated PVDF membrane shows higher wetting resistance, surface porosity, water contact angle, and $\mathrm{N}_{2}$ permeability. The performance of the produced membranes was examined for the Absorption of carbon dioxide in a gas-liquid contactor membrane through the solution of mono-ethanolamine (MEA). The results show that $\mathrm{CO}_{2}$ absorption flux of the PVDF hollow fiber membrane is higher than PSF hollow fiber membrane. The maximum $\mathrm{CO}_{2}$ absorption flux of $8.10 \times 10^{-3}\left(\mathrm{~mole} / \mathrm{m}^{2} \mathrm{~s}\right)$ at the liquid phase flow rate of $300 \mathrm{ml} / \mathrm{min}$ for PVDF hollow fiber membrane was achieved and also the maximum $\mathrm{CO}_{2}$ absorption flux of $6.50 \times 10^{-3}$ (mole/ $\mathrm{m}^{2} \mathrm{~s}$ ) at the liquid phase flow rate of $300 \mathrm{ml} / \mathrm{min}$ for PSF hollow fiber membrane was obtained. It can be concluded that a porous hydrophobic hollow fiber membrane with high surface porosity and high gas permeability can be a productive alternative for $\mathrm{CO}_{2}$ absorption through gas-liquid membrane contactors.
\end{abstract}

Keywords: hollow fiber membrane, gas-liquid contracting process, chemical absorption, PVDF, PSF

\section{Introduction}

Global warming is mainly due to greenhouse gas emissions, the major part of which is carbon dioxide gas ${ }^{[1-3]}$. Carbon capture and storage is one of several solutions recommended by the International Energy Agency to reduce the impact of human activities on the global climate. Using this technology may reduce carbon dioxide emissions by $14 \%$ to $17 \%{ }^{[4]}$. The technologies currently used in the gas confectionery industry to absorb carbon dioxide gas are dependent on the absorption of carbon dioxide by amine-based chemical solvents. Monoethanolamide (MEA) is currently the most important industrystandard solvent for the carbon dioxide capture process ${ }^{[5-6]}$. Upon absorption of carbon dioxide gas, the carbon dioxide gas released. The minimum energy required to absorption $90 \%$ of carbon dioxide gas from a coal-fired power plant is about $4-5 \%$ of the pure electricity produced by the same plant. Carbon dioxide gas absorption by monoethanolamide without compression is about 5 times the minimum energy required. The release of this gas in the air has increased the temperature of the planet. According to all the reasons for the improvement and economization of gas refining equipment, the removal of carbon dioxide from industrial streams and domestic use, and especially natural gas (down to mole\%), is essential because of the huge reserves of this critical substance in the country ${ }^{[7-9]}$. Extensive methods for removing carbon dioxide by Absorption in alkane amine ammonium solutions are available with conventional equipment, tray towers, bubble towers, filled towers, and spray towers. The use of alkane amines allows us to rehydrate the liquid solvent by simply heating. Therefore, a carbon dioxide capture process involves two major absorption and stripping units ${ }^{[10]}$. This process has operational problems such as overcrowding, channelization, persistence, and fatigue $\mathrm{e}^{[11-13]}$. Today, these processes are known as a suitable alternative to the traditional gas absorption processes with an amine solution. Membrane processes have major benefits to absorption processes. Lower power consumption, lower operating costs, less initial installation and investment, no risk of fire and explosion, being very suitable and compatible with environmental laws, etc. ${ }^{[14-17]}$. The 
nerve fiber membrane collision system is one of the preferred methods to be considered by researchers ${ }^{[18-20]}$. In this system, two-phase fluids collide with an appropriate membrane structure. For example, in a hollow fiber membrane, a common gas-liquid interface occurs at the mouth of the membrane pores ${ }^{[21-23]}$. Current developments in the chemical industry and similar industries have led to increased process speed and reduced energy consumption throughout the process ${ }^{[24-26]}$. One of the most important processes in such industries is the separation of different materials. To perform industrial processes, raw material components must often be separated and the product obtained from these processes must be separated and purified. On the other hand, in most industries, taking into account environmental laws, the need for separation processes is more than ever before ${ }^{[27]}$. In fact, as the separating processes and the related equipment are so large that in most industries, a large part of the cost of a product is related to the costs of separating and purifying the product ${ }^{[28]}$. For this reason, finding a simpler separation method at a lower cost can be considered. In choosing an appropriate separation method, the efficiency of those methods, access to equipment, separation costs, cost of construction and energy costs should be fully evaluated, taking into account environmental issues and policy issues ${ }^{[29]}$. Also, the separation targets must be specified in the process. In a separation process, different goals such as concentration, purification, separation, and displacement of the reaction balance can be considered. In this regard, membranes have been developed for the separation of various types of materials in solid, liquid, and gas states ${ }^{[30]}$. One of the most important factors is the type of polymer used in membrane fabrication. Typically the polymer used to make the membrane is for use in the hydrophobic gas-liquid membrane contactor system to prevent the penetration of the Absorption liquid into the membrane pores. The penetration of the Absorption liquid into the pores of the membrane will block the pores and reduce the level of contact between the gas and the liquid. This increases the mass transfer resistance and reduces the gas absorption flux ${ }^{[31-36]}$.

The penetration of water into the membrane pores reduces the contact surface between the gas and liquid and reduces the mass transfer rate. For this reason, in liquid-gas membrane contact systems, water-based polymers, such as poly (vinylidene fluoride), are commonly used. On the other hand, the structure and physical properties of the membrane, such as the diameter of the pores, total porosity, the critical pressure of water entering the pores, the angle of water contact with the membrane, also affect the membrane function. Therefore, it is necessary to study the performance of various polymers in the gas-liquid membrane contact system ${ }^{[37-42]}$. The mechanism of $\mathrm{CO}_{2}$ absorption is shown in Figure 1. Table 1 summarizes several findings of absorption performances that have been reported by various researchers for the past 10 years. Research objectives include the following:

1-Making a membrane of fiber between poly-sulfone and poly (vinylidene fluoride) in a phase separation method.

2-Determine the profile and structure of the membranes made.

3-Using membranes made to Absorption carbon dioxide gas by a 1 molar monoethanolamide aqueous solution in a gas and liquid membrane contact system.

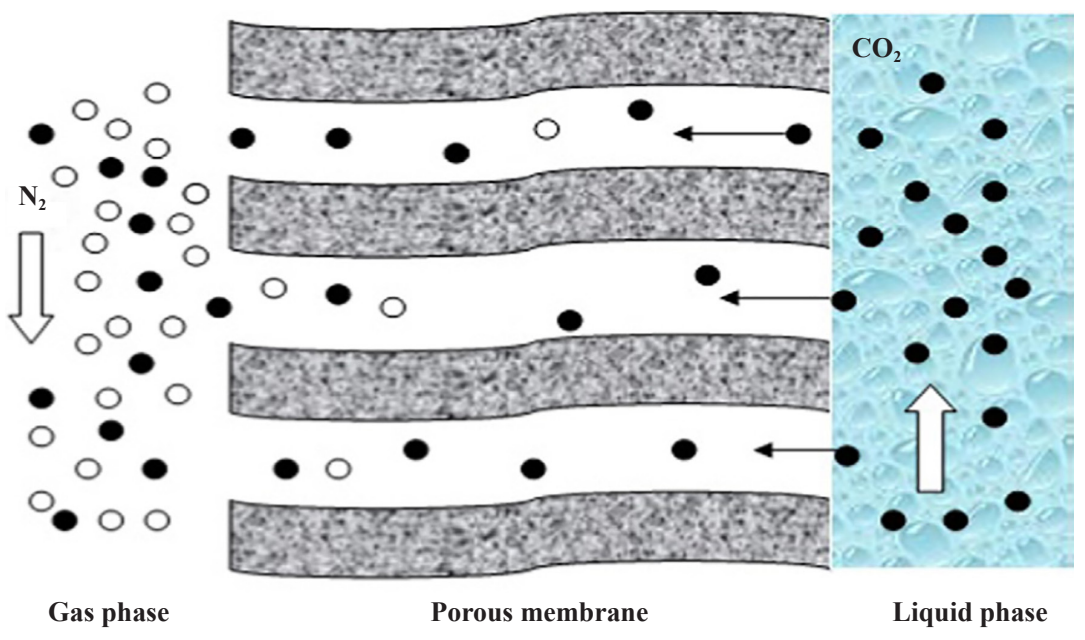

Figure 1. $\mathrm{CO}_{2}$ absorption phase gas-liquid membrane contactors system ${ }^{[27]}$ 
Table 1. Research findings on $\mathrm{CO}_{2}$ absorption flux by other researchers

\begin{tabular}{cccc}
\hline Membrane type & Liquid absorbent & $\mathrm{CO}_{2}$ absorption flux $\left(\right.$ mole $\left.^{-2} \mathrm{~s}^{-1}\right)$ & Reference \\
\hline HF PVDF & $1 \mathrm{M} \mathrm{MEA}$ & $8.0 * 10^{-3}$ & {$[61]$} \\
PTFE & $5 \mathrm{M} \mathrm{MEA}$ & $2.03 * 10^{-3}$ & {$[62]$} \\
PTFE & $0.03 \mathrm{AMP}$ & $1.08 * 10^{-4}$ & {$[63]$} \\
pp & $0.5 \mathrm{M} \mathrm{MEA}$ & $4.4 * 10^{4}$ & {$[64]$} \\
PVDF/triacetin & $0.5 \mathrm{M} \mathrm{NaOH}$ & $(1-3.2) * 10^{-3}$ & {$[65]$} \\
PVDF, PTFE & $2 \mathrm{M} \mathrm{MEA}$ & $1.08 * 10^{-2}$ & {$[66]$} \\
PVDF & $1 \mathrm{M} \mathrm{MEA}$ & $7.2 * 10^{-4}$ & {$[67]$} \\
PSF & $1 \mathrm{M} \mathrm{MEA}$ & $3.9 * 10^{-3}$ & {$[27]$} \\
\hline
\end{tabular}

\section{Materials and methods}

\subsection{Materials}

Poly-sulfone polymer Udel P-1700 (Solvay Advanced Polymers) and poly (vinylidene fluoride) Polymer Commercial (Kynar® $740, \mathrm{Mn}=156,000)$ from Arkema Inc. The USA were used to make the nylon fiber membrane. 1-methyl-2pyrrolidine (NMP $>99.5 \%$ ) was purchased from Merck, which was used as a non-purified solvent. Monoethanolamide (99\%) supplied by Sigma-Aldrich was used as a gas absorbent. Water was used as a coagulation bath in the process of making membranes ${ }^{[1,43-45]}$.

\subsection{Polymer solution preparation}

$18 \%$ by weight solutions of poly-sulfone and poly (vinylidene fluoride) polymers were prepared in the diethylamide solvent. To make any kind of polymer solution, the specified amount of solvent was weighed and poured into a glass bottle. Then, the specific amount of each weighted polymer was gradually added to the solvent so that the polymer beads did not clump together ${ }^{[46-50]}$. The solutions were stirred using a mechanical stirrer to dissolve all the polymer grains in the solvent. After the polymer grains were completely dissolved in the solvent, the solutions were placed in ultrasonic for 1 hour to remove air bubbles in the polymer solutions. If there is an air bubble in the polymer solution, the bubble is formed on the surface of the bubble and the membrane is torn. The viscosity of the polymer solutions was also measured using a Cole Parmer viscometer, EW-98965-40, USA. The composition of the materials used to make the polymer solutions and the viscosity of the solutions are shown in Table (2).

Table 2. Composition of the materials polymer solutions and the viscosity of the solutions

\begin{tabular}{ccc}
\hline polymer solutions & $\begin{array}{c}\text { Polymer } \\
\text { (Wt. \%) }\end{array}$ & $\begin{array}{c}\text { NMP } \\
\text { (Wt. \%) }\end{array}$ \\
\hline PSF & 18 & 82 \\
PVDF & 18 & 82 \\
\hline
\end{tabular}

\section{3 $\mathrm{CO}_{2}$ Absorption experiment}

The carbon dioxide gas uptake flux was measured with a $1 \mathrm{M}$ monoethanolamide solution in a gas-liquid membrane contact system. For this purpose, a set of mid-hollow fiber membranes containing 10 membranes was inserted in a stainless steel module as described in Table (3). Pure carbon dioxide gas using the pressure of the gas tank in the membrane conduit and the $1 \mathrm{M}$ monoethanolamide solution as a liquid adsorbent by pumping into the module shell and discordantly. The gas flow rate was constant at $200 \mathrm{ml} / \mathrm{min}$ and the fluid flow intensity varied in the range of $50-300 \mathrm{ml} / \mathrm{min}$. The gasphase pressure was set at 1 bar and the liquid phase pressure was 0.2 times higher than the gas phase pressure to prevent bubble formation in the liquid ${ }^{[51-53]}$. Carbon dioxide concentration was measured in the output fluid of the module by the titration method. To titrate $10 \mathrm{ml}$ of the output fluid from the module that absorbed carbon dioxide gas was poured into an Erlenmeyer and added $12 \mathrm{ml}$ of $1 \mathrm{M}$ sodium hydroxide $(\mathrm{NaOH})$ solution to dissolve the dissolved carbon dioxide gas. Not in the solution, there is completely ionized. Then $5 \mathrm{ml}$ of barium chloride solution $\left(\mathrm{BaCl}_{2}\right)$ was added to the solution. Then the obtained solution was shaken well until all the carbon dioxide dissolved in the solution (physically or chemically) deposit as barium carbonate $\left(\mathrm{BaCO}_{3}\right)$. The residual amount of sodium hydroxide in the solution was titrated with $\mathrm{HCl}$ and phenolphthalein was used as the reagent. The amount of hydrochloric acid used in this step is used to calculate the amount 
of carbon dioxide absorbed as a mole of carbon dioxide per mole of monoethanolamide. Before sampling for titration, the gas uptake test was performed in the gas-liquid membrane contactor system for 30 min to standardize the test conditions. The amount of hydrogen chloride $(\mathrm{HCl})$ is used in this stage to calculate the amount of carbon dioxide Absorption by the moles of carbon dioxide $\left(\mathrm{CO}_{2}\right)$ to the number of moles of Mono-ethanol amine (MEA). Before taking samples, all tests were performed for 30 minutes to achieve a steady state.

$$
M_{\mathrm{CO}_{2}}\left(\frac{m o L}{L}\right)=\frac{(N . V)_{H C L}}{V_{\text {sample }}}
$$

The total area of the membrane was considered as the surface liquid-gas contact deal for mass transfer, so the empirical amount of carbon dioxide flux $J_{\mathrm{CO}_{2}}\left(\frac{\mathrm{mol}}{V_{\text {sample }}}\right)$ is calculated from the following relation:

$$
J_{\mathrm{CO}_{2}}=\frac{Q_{L} \cdot M_{\mathrm{CO}_{2}}}{V_{\text {sample }}} * 1000
$$

Where $Q_{L}$ is Absorption flow rate $\left(\mathrm{m}^{3} \mathrm{~s}^{-1}\right), M_{\mathrm{CO}_{2}}$ is the concentration of carbon dioxide in the Absorption solution $(\mathrm{mol} / \mathrm{L})$ and $\mathrm{A}_{\mathrm{i}}$ is the collision surface between air-liquid $\left(\mathrm{m}^{2}\right)$. Absorption membrane contactor-module output flow rate was measured by a liquid flow meter. Gas-liquid contact surface is measured based on Absorption flow on the pipe or the surface contact module. When the liquid Absorption flows on the shell side, the surface area is calculated using the following relation:

$$
A_{0}=n \pi d_{i} L
$$

Where $n$ is the number of fibers (in this study, 10), $d_{i}$ is inner diameter of fibers, and (m) and L are effective fiber length. In this system, two-phase fluid system uses a membrane structure appropriate to collide. For example, the shared level of gas-liquid is created in the opening of membrane pore. Gas-liquid hollow fiber membrane contactor can be a promising alternative for the $\mathrm{CO}_{2}$ absorption processes. In this system, the porous membrane acts as a fixed interface between the gas and liquid phases without dispersing one phase into another. The form of the pilot reactor is shown in Figure 2 .

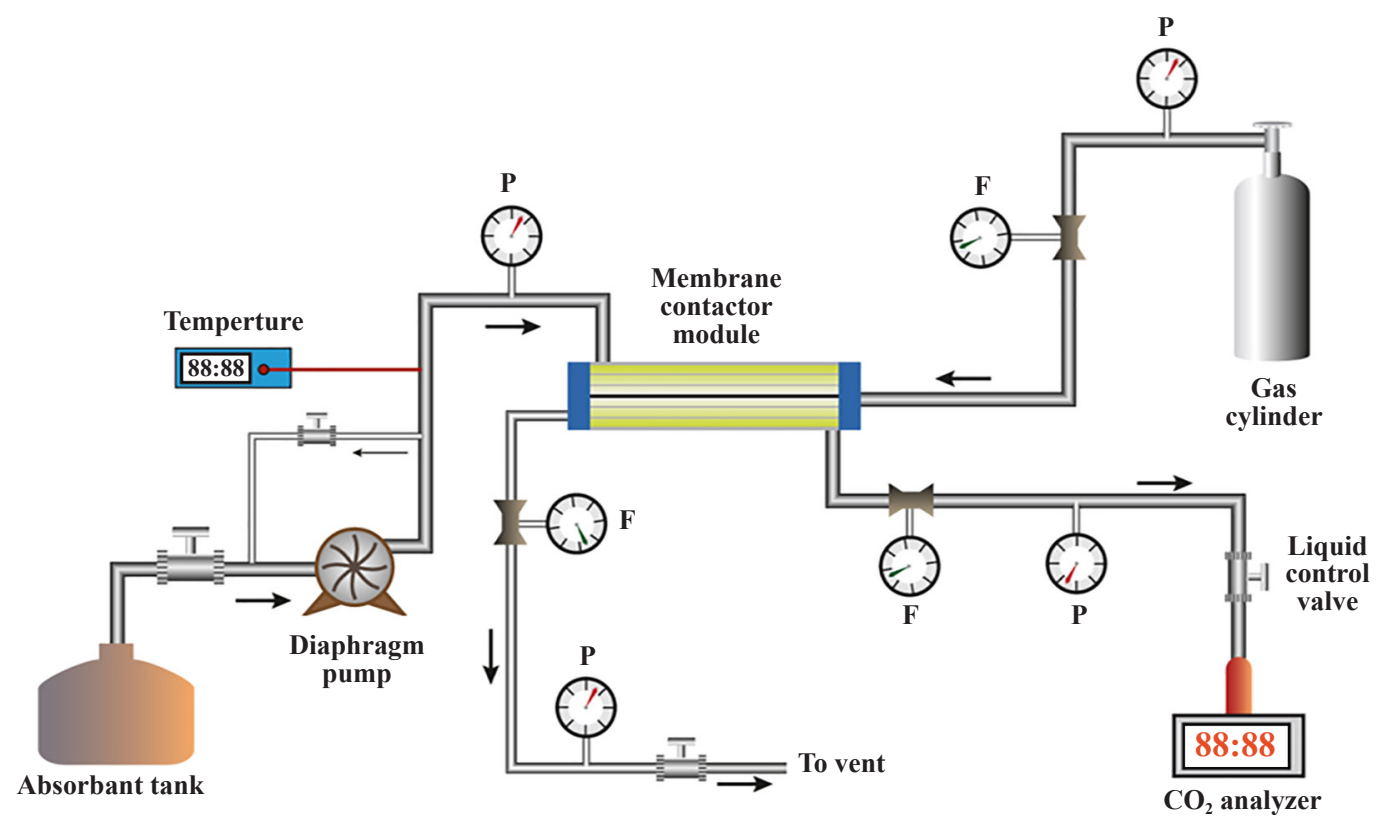

Figure 2. Absorption carbon dioxide system ${ }^{[27]}$ 
Table 3. Properties of fabricated PSF and PVDF hollow fiber membranes

\begin{tabular}{cc}
\hline Dope extrusion rate (ml/min) & 4.5 \\
\hline Bore composition (wt. \%) & $80 / 200$ NMP/Water \\
Bore flow rate (ml/min) & 1.55 \\
external coagulant & Tap water \\
Air gap distance $(\mathrm{cm})$ & 0.0 \\
the outer diameter of the inner spinner $(\mathrm{mm})$ & $0.55-1.2$ \\
Spinning dope temperature $\left({ }^{\circ} \mathrm{C}\right)$ & 25 \\
External coagulant temperature $\left({ }^{\circ} \mathrm{C}\right)$ & 25 \\
The inner diameter of the module $(\mathrm{mm})$ & 14 \\
Length of the module $(\mathrm{mm})$ & 270 \\
Output diameter fiber $(\mathrm{mm})$ & $0.70-0.90$ \\
Input diameter of fibers $(\mathrm{mm})$ & $0.45-0.50$ \\
The effective length of fiber $(\mathrm{mm})$ & 150 \\
The number of fibers & 10 \\
Contact area & 4521 in \\
\hline
\end{tabular}

\subsection{Fabrication and characterization of porous hollow fiber membranes}

PVDF and PSF Polymer (PSF and PVDF Udel P-1700-Solvay Advance Polymer) for the building hollow fiber membranes: 1-methyl, 2-pyrrolidone (NMP $>99.5 \%$ ) as a gross solvent and ethanol as non-solvent additives were purchased from Merck Company Germany. In all cases tap water was used as coagulation bath (spinning process). Monoethanol amine (MEA > 98\%) was purchased from Sigma-Aldrich Co and used as the absorbent liquid. Table 2 and table 3 shows the Properties of fabricated PVDF and PSF hollow fiber membranes. dope was applied as an external coagulant for solidification of polymer solution resulting in formation of hollow fiber. After that the Spinneret hollow fiber was drowned into the water for three days to remove the ethanol and remaining NMP. Then it was naturally hung to be dried in environment temperature for one to two days.

\section{Results and Discussion}

The cross-sectional and internal surface structure of the membranes made by scanning electron microscopy was investigated. Figures 3 and 4 show the cross-sectional and internal surfaces of the nylon fibers. The membranes have an external diameter of from 0.70 to $0,90 \mathrm{~mm}$, the inner diameter is from 0,45 to $0,50 \mathrm{~mm}$ and the wall thickness is from 0,225 to $0,250 \mathrm{~mm}$. Because all the membranes were made at the same rate of discharge of the polymer solution and the diffusion fluid flow rate, they were approximately equal in size. In general, the structure of the membrane depends on the rate of change in the phase of the polymer solution in the phase separation process. The change in the phase of the polymer solution depends on the viscosity of the polymer solution. A polymer solution with a viscosity has a faster phase change. The viscosity of the polymer solution affects the penetration rate of the coagulant to the membrane structure, so the less viscosity of the polymer solution results in a finger-shaped structure. The viscosity of polymer solutions is presented in Table 4. The cross-sectional images of the poly (vinylidene fluoride) membrane indicate that a thick sponge layer is formed in the middle of the membrane that is surrounded by a low thickness finger structure on the inner and outer surfaces of the membrane. Due to the hydrophobicity of the polymer of poly (vinylidene fluoride), the phase separation process is slow during the construction of this membrane, which can be attributed to the formation of a thick sponge layer in this membrane. As shown in Figures 3 (A) and (B), the poly-sulfone membrane cross-section has a thick thumb structure near the outer surface of the membrane, with a low thickness foam structure near the inner surface of the membrane. According to Table 4, the viscosity of the solution of poly-sulfone is determined from the viscosity of the solution the less poly(vinylidene fluoride) is due to the formation of the thickening of the fingers of this membrane. Due to the use of water (non-solvent) in the coagulation bath, the fingertip is formed at the outer surface of the poly-sulfone membrane because water as a non-solvent polymer separation rate accelerates the phase. From Figures 3 and $4(C)$, it is understood that the use of high solvent concentration as Figures 3 and 4 (C) disintegrate slows down the phase separation process and forms 
an unclosed inner surface with an open structure with a finer porosity and is the same structure of the study for Polyvinyl dine Fluoride membranes using $90 \%$ by weight of solvent as a fluid ${ }^{[54-56]}$. Removal of the inner shell of the membrane could reduce the membrane's resistance to mass transfer in the gas absorption process.
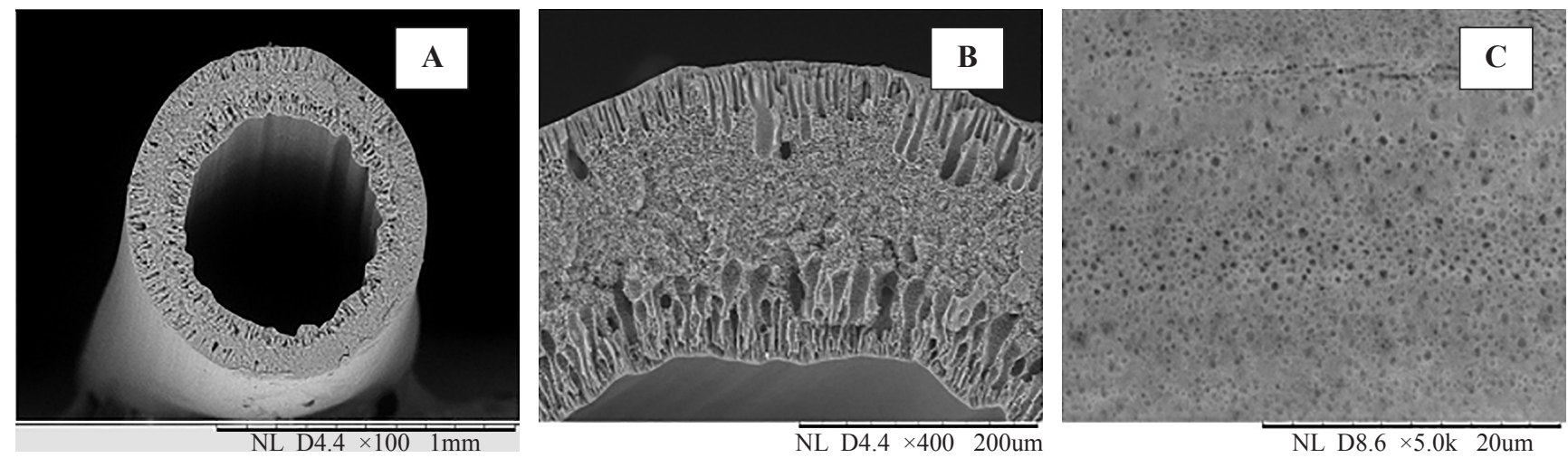

Figure 3. SEM cross-sectional images (A), cross-sectional area (B) and internal surface (C) of the fibers of the poly(vinylidene fluoride) (M1)
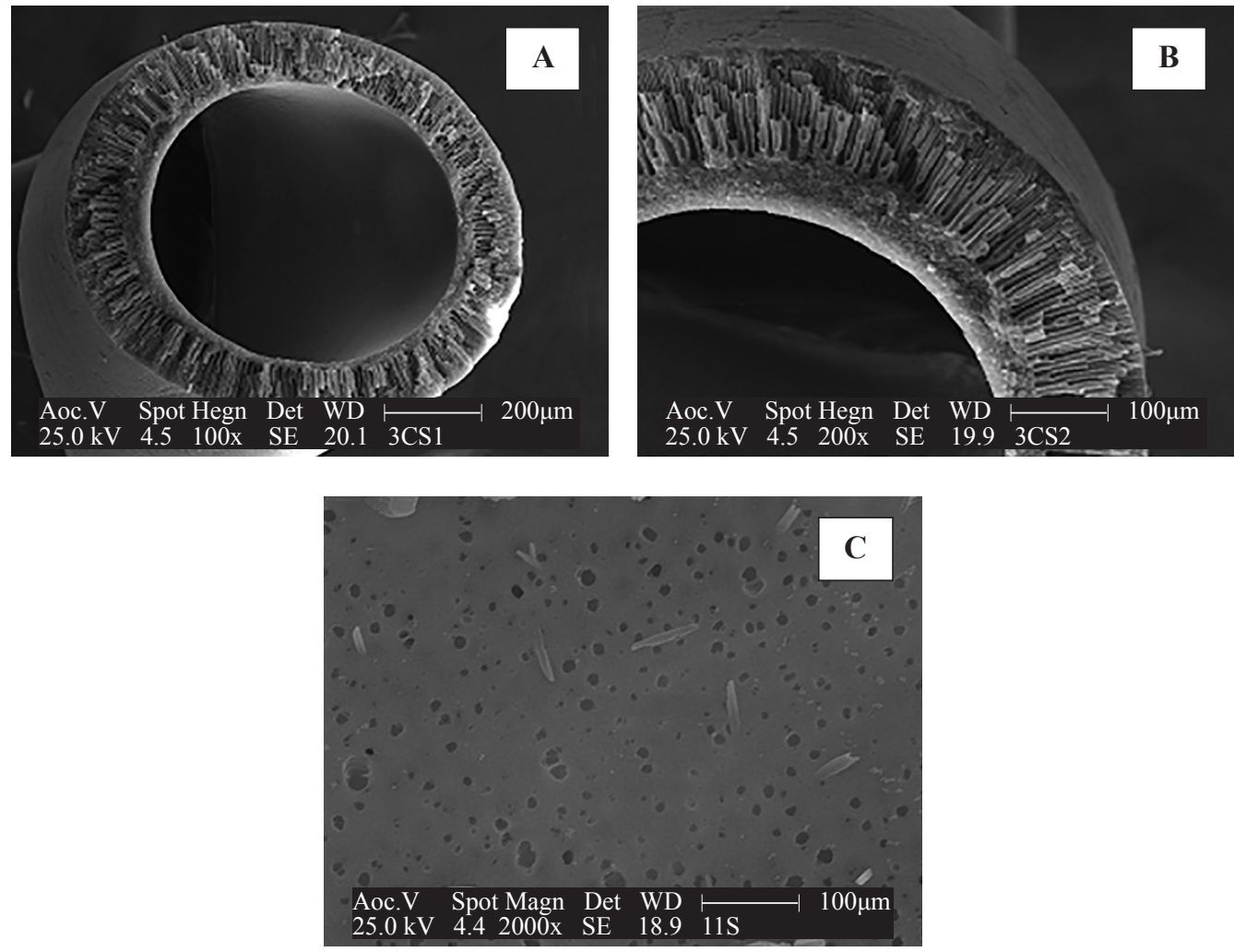

Figure 4. SEM cross-sectional images (A), cross-sectional area (B) and internal surface (C) of the fibers of the PSF (M1)

Table 4. Viscosity polymer solutions

\begin{tabular}{cc}
\hline polymer solutions & Viscosity polymer solutions $\left(\mathrm{cp}\right.$ at $\left.25^{\circ} \mathrm{C}\right)$ \\
\hline PVDF & 2815.3 \\
PSF & 930.6 \\
\hline
\end{tabular}

\subsection{Characteristics of membrane}

The results of measuring the average pore size, effective porosity, critical pressure input, total porosity and contact angle of the membrane surface with the water of poly (vinylidene fluoride) and poly-sulfone membranes are presented in Table 5. In the process of making asymmetric membranes, the overall porosity of the membrane can be controlled using 
the relative composition of the material in the polymer solution. As shown in Table 5, the porosities of poly (vinylidene fluoride) and poly-sulfone membranes are $72.21 \%$ and $71.41 \%$, respectively. The high porosity of the membranes produced is due to the low concentration of polymer in the polymer solution. To assess the resistance of the membranes to wetting, a critical pressure input test (CEPw) was performed. In the gas-liquid membrane contact, the membrane holes must be filled with gas and prevent the introduction of liquid into the membrane pores. The introduction of absorbent liquid into the membrane pores reduces the contact between the gas and liquid and increases the resistance of the membrane mass transfer. Therefore, the use of high-resistance wetting membranes against wetting is preferred for gas-gas applications in liquid-gas membrane contactor. As can be seen from Table 3, the membrane of the poly (vinylidene fluoride) fiber has a greater CEPw value than the nylon fiber membrane of the poly-sulfone. As already mentioned, poly (vinylidene fluoride) polymer is more hydrophobic than poly-sulfone polymer. Therefore, further hydrophobicity of the poly (vinylidene fluoride) membrane increases the contact angle with this membrane water and also increases the CEPw of this membrane. Figure 5 shows the penetration of nitrogen gas $\left(\mathrm{N}_{2}\right)$ for average pressure values. According to the data of Table 5 and Figure 5 , the nitrogen gas permeability in the membrane of the poly (vinylidene fluoride) fiber membrane is higher than the poly-sulfone membrane. The higher the gas permeability in this membrane the average pore size of the membrane is larger. The chemical carbon dioxide gas test was carried out using a 1 molar monoethanolamide solution in a gas-liquid membrane contactor. Liquid adsorbent flows in the shell of the module and contact with the skin layer of the membranes, and pure carbon dioxide gas flows in the direction of the membrane cavity in the opposite direction to the liquid flow. The amount of carbon dioxide gas absorption of membranes was measured and compared with the change in the intensity of the adsorbent fluid flow. The results of the experiments on carbon dioxide gas adsorption in terms of fluid flow intensity are shown in Figure 6. Based on Figure 6, the flux absorption of carbon dioxide in both membranes increases with increasing absorption fluid flow due to the reduction in the thickness of the boundary layer of the liquid around the fibers by increasing the liquid velocity, which leads to a decrease in the fluid transfer mass transfer resistance. Also, with increasing fluid velocity, the flow regime changes from relaxed to turbulent, which results in the absorption of more carbon dioxide gas. As shown in Figure 6, in low currents from absorbing fluid, the carbon dioxide gas absorption flux increases both slowly and with gentle gradients, and the liquid flow rate is about $150(\mathrm{ml} / \mathrm{min})$ the slope of the gas absorption flux significantly increases, indicating a decrease in the thickness of the boundary layer around the fibers. It is also seen from Figure 6 that the adsorption rate of the poly (vinylidene fluoride) membrane gas is higher than that of the poly-sulfone membrane. As seen from the results of the specification of the membrane, the contact angle of the Polyvinyl dine Fluoride fiber membrane is greater than the polysulfone membrane, so the penetration of water into the pores of the poly-sulfone membrane is easier than the poly (vinylidene fluoride) membrane, and as this membrane is in the early stages of the process absorption gets wet. In this case, the membrane resistance controls the mass transfer process. The wetting of the membrane can increase the total transfer mass resistance and greatly affects the absorption flux ${ }^{[57-61]}$. Also, the effective porosity of the poly (vinylidene fluoride) membrane surface is much higher than that of the poly-sulfone membrane, resulting in a higher level of liquid and gas contact in the membrane than the poly-sulfone membrane, which increases the mass transfer rate. At the intrinsic intensity of the adsorbent flow of $300 \mathrm{ml} / \mathrm{min}^{-1}$, the maximum flux of carbon dioxide gas is $8.10 \times 10^{-3}\left(\mathrm{~mole} / \mathrm{m}^{2} \mathrm{~s}\right)$ and $6.50 .10 \times 10^{-3}$ $\left(\mathrm{mole} / \mathrm{m}^{2} \mathrm{~s}\right)$ to an arrangement was made for the poly (vinylidene fluoride) and poly-sulfone naphthenic membrane.

Table 5. Specifications of hollow fiber membranes made of PSF and PVDF

\begin{tabular}{ccc}
\hline membranes & PSF & PVDF \\
\hline The average pore size $(\mathrm{nm})$ & 13.42 & 21.18 \\
Effective surface porosity $\left(\varepsilon / \mathrm{Lp}\left(10 \mathrm{~m}^{-1}\right)\right.$ & 546 & 1250 \\
Critical pressure of water entry $\left(\times 10^{5} \mathrm{~Pa}\right)$ & 5.50 & 7.00 \\
Total porosity $(\%)$ & 71.41 & 72.21 \\
Membrane braking pressure $\left(\times 10^{5} \mathrm{~Pa}\right)$ & 8.50 & 9.50 \\
Contact ratio with water & 64.32 & 81.23 \\
\hline
\end{tabular}




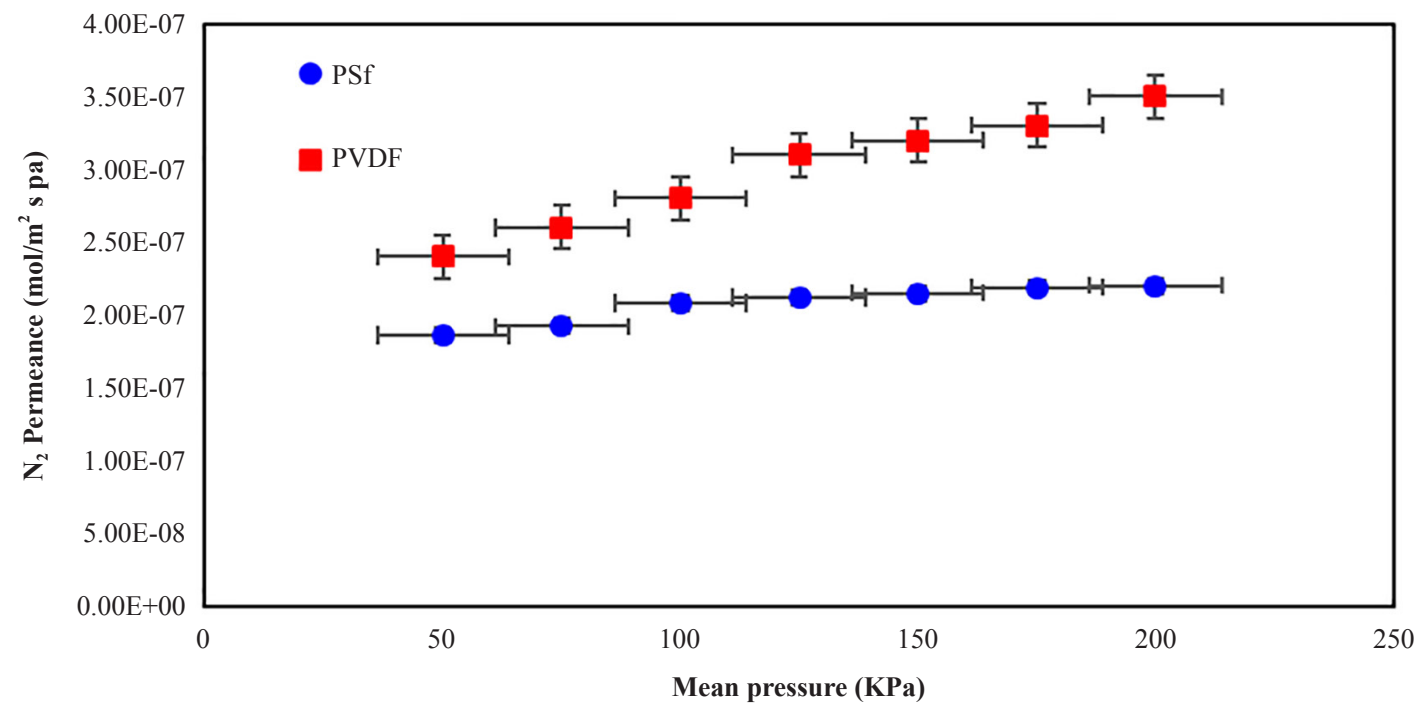

Figure 5. The amount of permeability Absorption of $\mathbf{N}_{2}$ as a function of the average pressure of the hollow fiber membranes

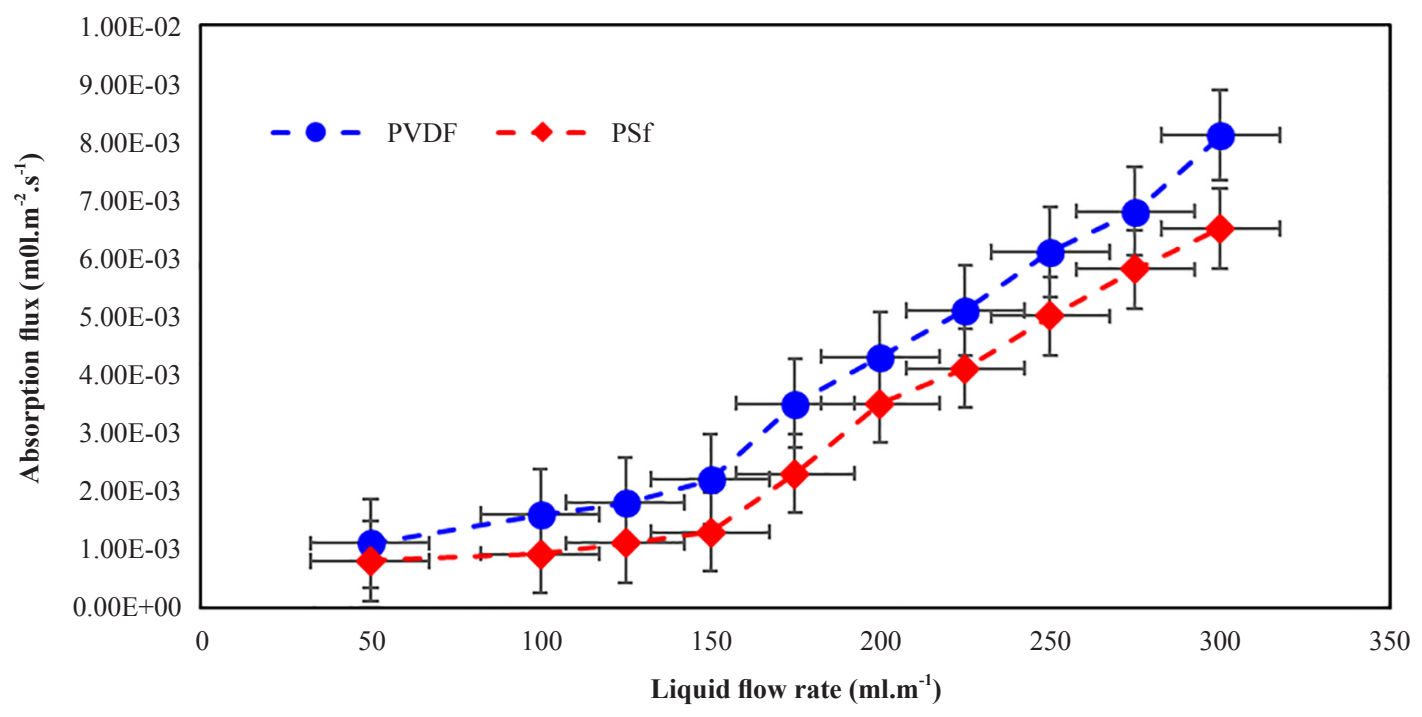

Figure 6. The effect of absorption flow rate (MEA) on the absorption of $\mathrm{CO}_{2}$ in gas-liquid membrane contactors

\subsection{Comparison of long-term carbon dioxide absorption gas hollow fiber membranes}

To investigate the applicability of the membrane made in long-term carbon dioxide absorption gas hollow fiber membranes with distilled water, the long-term carbon dioxide absorption gas hollow fiber membranes experiment was carried out for $170 \mathrm{~h}$ (approximately 1 week) at ambient temperature, with the results shown in Figure 7. The results of long term $\mathrm{CO}_{2}$ absorption experiment showed that the $\mathrm{CO}_{2}$ absorption flux of the PVDF membrane decreased about $76 \%$ and reached to $6.88 \times 10^{-3}\left(\mathrm{~mol} \mathrm{~m}^{-2} \mathrm{~s}^{-1}\right), 20 \mathrm{~h}$ after the beginning of the process. The $\mathrm{CO}_{2}$ absorption flux of the PSF membrane decreased by about $24 \%$ and reached $9.75 \times 10^{-3}\left(\mathrm{~mol} \mathrm{~m}^{-2} \mathrm{~s}^{-1}\right), 70 \mathrm{~h}$ after the beginning of the process. The hollow fiber membrane made with poly (vinylidene fluoride) polymer withstands moisture for up to 20 hours from the start of the process and exhibits an almost constant gas absorption flux, while the membrane made with polysulfide has withstood moisture for 70 hours. These factors make the polysulfone membrane more resistant to the penetration of the adsorbent liquid and therefore have a longer resistance to moisture. Also, the drop in absorption flux of the polysulfone membrane is significantly lower than that of the other membrane, indicating higher resistance to moisture. 


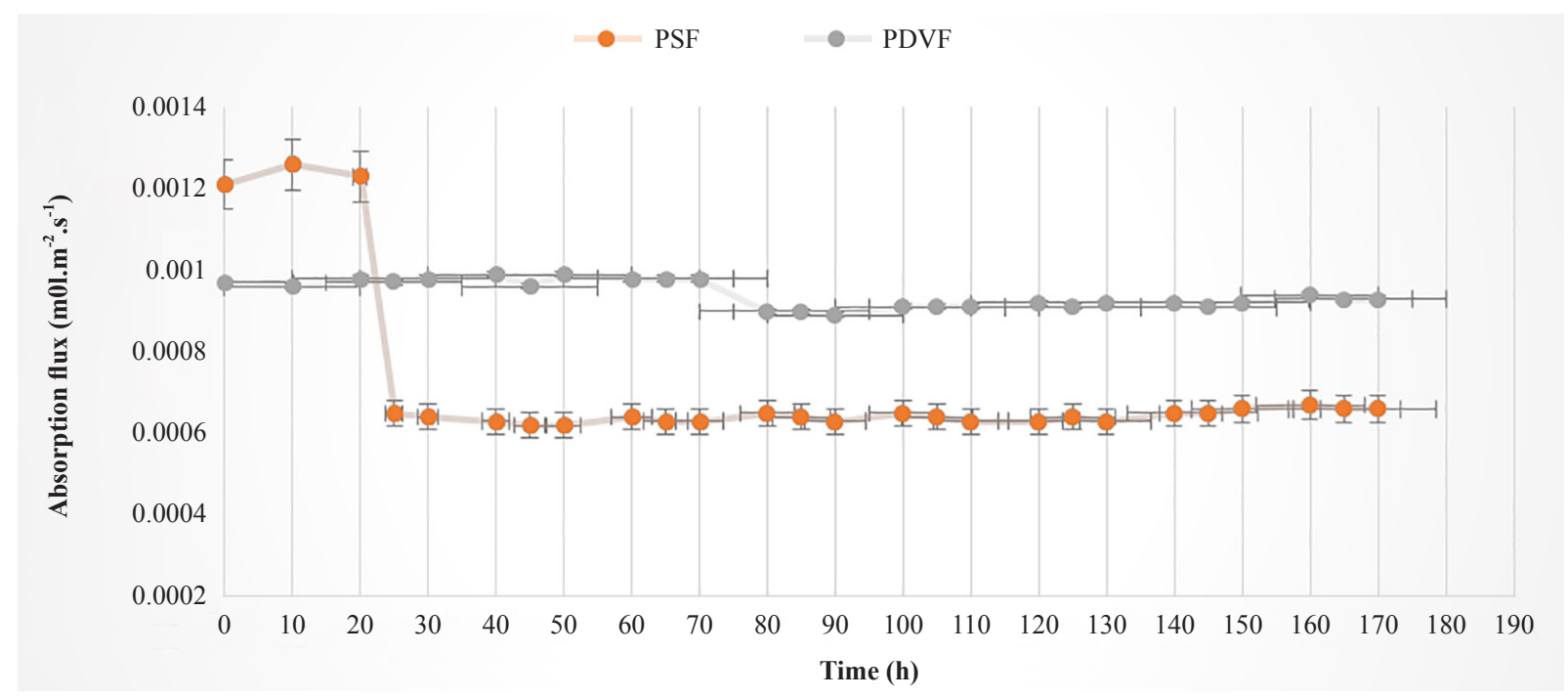

Figure 7. The carbon dioxide absorption flux over time

\section{Conclusion}

In this study, fiber membranes were made between poly (vinylidene fluoride) and poly-sulfone in a wet phase separation method. They were used for chemical absorption of carbon dioxide gas by 1 molar monoethanolamide solution in the gas-liquid membrane contact system. The results show that the total porosity of membranes is $72.71 \%$ and $71.41 \%$, which is a high amount of porosity of the membranes because of the low concentration of polymer in the polymer solution. The critical pressure of the water inlet of the poly (vinylidene fluoride) membrane is significantly higher than the polysulfone membrane, which is due to the greater hydrophobicity of the membrane. Nitrogen gas permeability has increased for both membranes with increasing gas pressure, and this increase is higher for poly (vinylidene fluoride) membranes. The carbon dioxide gas absorption flux of both membranes increases with increasing absorption liquid velocity. Using a membrane made of Polyvinyl dine Fluoride polymer, the maximum flux absorption of $8.10 * 10^{-3}$ molar $/ \mathrm{m}^{2}$ in $300 \mathrm{ml} / \mathrm{min}$ was obtained from the adsorbent flow rate.

\section{References}

[1] J. J. Cai, K. Hawboldt, M. Abedinzadegan Abdi. Improving gas absorption efficiency using a novel dual membrane contactor. Journal of Membrane Science. 2016; 510: 249-258.

[2] M. Vahidi, N. Seyed Matin, M. Goharrokhi, et al. Correlation of $\mathrm{CO}_{2}$ solubility in N-methyl diethanolamine + piperazine aqueous solutions using extended Debye-Hückel model. The Journal of Chemical Thermodynamics. 2009; 41(11): 1272-1278.

[3] J. J. Cai, K. Hawboldt, M. Abedinzadegan Abdi. Contaminant removal from natural gas using dual hollow fiber membrane contactors. Journal of Membrane Science. 2012; 397-398(15): 9-16.

[4] P. Iovane, F. Nanna, Y. Ding, et al. Experimental test with polymeric membrane for the biogas purification from $\mathrm{CO}_{2}$ and $\mathrm{H}_{2}$ S. Fuel. 2014; 135: 352-358.

[5] Rami Faiz, M. Al-Marzouqi. Insights on natural gas purification: Simultaneous absorption of $\mathrm{CO}_{2}$ and $\mathrm{H}_{2} \mathrm{~S}$ using membrane contactors. Separation and Purification Technology. 2011; 76(3): 351-361.

[6] P. Luis, T. V. Gerven, B. V. D. Bruggen. Recent developments in membrane based technologies for $\mathrm{CO}_{2}$ capture. Prog. Energy combust. 2012; 38: 419-448.

[7] Gigi George, Nidhika Bhoria, Sama AlHallaq, et al. Polymer membranes for acid gas removal from natural gas. Separation and Purification Technology. 2016; 158: 333-356.

[8] M. Rahbari-Sisakht, A. F. Ismail, D. Rana, et al. Effect of SMM concentration on morphology and performance of surface modified PVDF hollow fiber membrane contactor for $\mathrm{CO}_{2}$ absorption. Separation and Purification Technology. 2013; 116(15): 67-22.

[9] M. Rahbari-Sisakht, A. F. Ismail, D. Rana, et al. Carbon dioxide stripping from diethanolamine solution through porous surface modified PVDF hollow fiber membrane contactor. Journal of Membrane Science. 2013; 425: 270-275.

[10] B. D. Bhide, A. Voskericyan, S. A. Stern. Hybrid processes for the removal of acid gases from natural gas. Journal of 
Membrane Science. 1998; 140(1): 27-49.

[11] A. Mansourizadeh, A. F. Ismail. Effect of additives on the structure and performance of polysulfone hollow fiber membranes for $\mathrm{CO}_{2}$ absorption. Journal of Membrane Science. 2010; 348(1-2): 260-267.

[12] Gholamreza Bakeri, Ahmad Fauzi Ismail, Mojtaba Shariaty-Niassar. Effect of polymer concentration on the structure and performance of polyetherimide hollow fiber membranes. Journal of Membrane Science. 2010; 363(1-2): $103-111$.

[13] R. Naimabc, A. F. Ismailab, A. Mansourizadehd. Preparation of microporous PVDF hollow fiber membrane contactors for $\mathrm{CO}_{2}$ stripping from diethanolamine solution. Journal of Membrane Science. 2012; 392-393: 29-37.

[14] M. Rahbari-Sisakht, A. F. Ismail, T. Matsuura. Development of asymmetric polysulfone hollow fiber membrane contactor for $\mathrm{CO}_{2}$ absorption. Separation and Purification Technology. 2012; 86: 215-220.

[15] M. Rahbari-Sisakht, A. F. Ismail, D. Rana, et al. Effect of different additives on the physical and chemical $\mathrm{CO}_{2}$ absorption in polyetherimide hollow fiber membrane contactor system. Separation and Purification Technology. 2012; 98: 472-480.

[16] A. Mansourizadeh, A. Ismail, M. Abdullah, et al. Preparation of polyvinylidene fluoride hollow fiber membranes for $\mathrm{CO}_{2}$ absorption using phase inversion promoter additives. Journal of Membrane Science. 2010; 355(1-2): 200-207.

[17] A. F. Ismaila, I. R. Dunkinb, S. L. Gallivanb, et al. Production of super selective polysulfone hollow fiber membranes for gas Separation. Polymer. 1999; 40(23): 6499-6506.

[18] Patricia Luis, Bart Van der Bruggen, Tom Van Gerven. Non-dispersive absorption for $\mathrm{CO}_{2}$ capture: From the laboratory to industry. Journal of Chemical Technology \& Biotechnology. 2011; 86(6): 769-775.

[19] Rahbari-Sisakht M., Ismail A. F., Matsuura T. Effect of bore fluid composition on structure and performance of asymmetric polysulfone hollow fiber membrane contactor for $\mathrm{CO}_{2}$ absorption. Sep. Purif. Technol. 2012; 88: 99-106.

[20] Sakarin Khaisria, Davidde Montignyb, Paitoon Tontiwachwuthikulb, et al. $\mathrm{CO}_{2}$ stripping from monoethanolamine using a membrane contactor. Journal of Membrane Science. 2011; 376(1-2): 110-118.

[21] Jing-Liang Li, Bing-Hung Chen. Review of $\mathrm{CO}_{2}$ absorption using chemical solvents in hollow fiber membrane contactors. Separation and Purification Technology. 2005; 41(2): 109-122.

[22] Huseni A. Rangwala. Absorption of carbon dioxide into aqueous solutions usinghollow fiber membrane contactors. Journal of Membrane Science. 1996; 112(2): 229-240.

[23] Dongliang Wang, K Li, W. K Teo. Porous PVDF asymmetric hollow fiber membranes prepared with the use of small molecular additives. Journal of Membrane Science. 2000; 178(1-2): 13-23.

[24] R. Naim, A. F. Ismail, A. Mansourizadeh. Preparation of microporous PVDF hollow fiber membrane contactors for $\mathrm{CO}_{2}$ stripping from diethanolamine solution. Journal of Membrane Science. 2012; 392-393: 29-37.

[25] R. Naim, A. F. Ismail. Effect of polymer concentration on the structure and performance of PEI hollow fiber membrane contactor for $\mathrm{CO}_{2}$ stripping. Journal of Hazardous Materials. 2013; 250-251: 354-361.

[26] Seung-Hak Choi, Franco Tasselli, Johannes C. Jansena, et al. Effect of the preparation conditions on the formation of asymmetric poly(vinylidene fluoride) hollow fibre membranes with a dense skin. European Polymer Journal. 2010; 46(8): 1713-1725.

[27] Kianfar E, Pirouzfar V, Sakhaeinia H. An experimental study on absorption/stripping $\mathrm{CO}_{2}$ using Mono-ethanol amine hollow fiber membrane contactor. J. Taiwan Inst. Chem. Eng. 2017; 80: 954-962.

[28] Salimi M, Pirouzfar V, Kianfar E. Enhanced Gas Transport Properties in Silica Nanoparticles Filler Polystyrene Nanocomposite Membranes. Colloid Polym. Sci. 2017; 295: 215-226.

[29] Mahmoud Salimi, Vahid Pirouzfar, Ehsan Kianfar. Novel nanocomposite membranes prepared with PVC/ABS and silica nanoparticles for $\mathrm{C}_{2} \mathrm{H}_{6} / \mathrm{CH}_{4}$ separation. Polymer Science, Series A. 2017; 59: 566-574.

[30] Ehsan Kianfar, Mahmoud Salimi, Farshid Kianfar, et al. $\mathrm{CO}_{2} / \mathrm{N}_{2}$ separation using polyvinyl chloride iso-phthalic acid/ aluminium nitrate nanocomposite membrane. Macromolecular Research. 2019; 27(1): 83-89.

[31] Ma H, Hsiao BS, Chu B. Functionalized electrospun nanofibrous microfiltration membranes for removal of bacteria and viruses. J Memb Sci. 2014; 452: 446.

[32] Wang Z, Yu H, Xia J, et al. Novel GO-blended PVDF ultrafiltration membranes. Desalination. 2012; 299 : 50-54.

[33] Stamatialis DF, Papenburg BJ, Gironés M, et al. Medical applications of membranes: Drug delivery, artificial organs and tissue engineering. J Memb Sci. 2008; 308: 1-34.

[34] Dong G, Woo KT, Kim J, et al. Simulation and feasibility study of using thermally rearranged polymeric hollow fiber membranes for various industrial gas separation applications. J Memb Sci. 2015; 496: 229-241.

[35] Zhang X, Chen Y, Konsowa AHH, et al. Evaluation of an innovative polyvinyl chloride (PVC) ultrafiltration membrane for wastewater treatment. Sep Purif Technol. 2009; 70: 71-78.

[36] Wang C, Wu H, Qu F, et al. Preparation and properties of polyvinyl chloride ultrafiltration membranes blended with functionalized multi-walled carbon nanotubes and MWCNTs/ $\mathrm{Fe}_{3} \mathrm{O}_{4}$ hybrids. Journal of Applied Polymer Science. 2016; 43417: 1-8.

[37] Roy KJ, Anjali T V., Sujith A. Asymmetric membranes based on poly (vinyl chloride): Effect of molecular weight of 
additive and solvent power on the morphology and performance. J Mater Sci. 2017; 52: 5708-5725.

[38] Xu J, Xu Z-LL. Poly (vinyl chloride) (PVC) hollow fiber ultrafiltration membranes prepared from PVC/additives/ solvent. J Memb Sci. 2002; 208: 203-212.

[39] Teow YH, Ooi BS, Ahmad AL. Fouling behaviours of $\mathrm{PVDF}^{-\mathrm{TiO}_{2}}$ mixed-matrix membrane applied to humic acid treatment. Journal of Water Process Engineering. 2017; 15: 89-98.

[40] Gao W, Liang H, Ma J, et al. Membrane fouling control in ultra filtration technology for drinking water production: A review. DES. 2011; 272: 1-8.

[41] Sadeghi M, Chenar MP, Rahimian M, et al. Gas Permeation Properties of Polyvinylchloride/Polyethyleneglycol Blend Membranes. 2008; 110(2): 1-6.

[42] Behboudi A, Jafarzadeh Y, Yegani R. Polyvinyl chloride/polycarbonate blend ultrafiltration membranes for water treatment. J Memb Sci. 2017; 534: 18-24.

[43] Yang YF, Wan LS, Xu ZK. Surface hydrophilization for polypropylene microporous membranes: A facile interfacial crosslinking approach. J Memb Sci. 2009; 326: 372-381.

[44] Rabiee H, Mahdi S, Shahabadi S, et al. Enhancement in permeation and antifouling properties of PVC ultrafiltration membranes with addition of hydrophilic surfactant additives: Tween-20 and Tween-80. Journal of Environmental Chemical Engineering. 2006; 4: 4050-4061.

[45] Fan X, Su Y, Zhao X, et al. Fabrication of polyvinyl chloride ultrafiltration membranes with stable antifouling property by exploring the pore formation and surface modification capabilities of polyvinyl formal. J Memb Sci. 2014; 464: 100-109.

[46] Yong L, Wahab A, Peng C, et al. Polymeric membranes incorporated with metal/metal oxide nanoparticles: A comprehensive review. DES. 2013; 308: 15-33.

[47] Rabiee H, Vatanpour V, Farahani MHDA, et al. Improvement in flux and antifouling properties of PVC ultrafiltration membranes by incorporation of zinc oxide (ZnO) nanoparticles. Sep Purif Technol. 2015; 156: 299-310.

[48] Zhang Y, Cui P, Du T, et al. Development of a sulfated Y-doped nonstoichiometric zirconia/polysulfone composite membrane for treatment of wastewater containing oil. Sep Purif Technol. 2009; 70: 153-159.

[49] Ng LY, Leo CP, Mohammad AW. Optimizing the incorporation of silica nanoparticles in polysulfone/poly(vinyl alcohol) membranes with response surface methodology. J Appl Polym Sci. 2011; 121: 1804-1814.

[50] Yang Y, Zhang H, Wang $\mathrm{P}$, et al. The influence of nano-sized $\mathrm{TiO}_{2}$ fillers on the morphologies and properties of PSF UF membrane. J Memb Sci. 2007; 288: 231-238.

[51] Yuanyuan Zhao, Jiaqi Lu, Xuyang Liu, et al. Performance enhancement of polyvinyl chloride ultrafiltration membrane modified with graphene oxide. J Colloid Interface Sci. 2016; 480: 1-8.

[52] Dorosti F, Omidkhah MR, Pedram MZ, et al. Fabrication and characterization of polysulfone/polyimide-zeolite mixed matrix membrane for gas separation. Chem Eng J. 2011; 171: 1469-1476.

[53] Goh PS, Ismail AF, Sanip SM, et al. Recent advances of inorganic fillers in mixed matrix membrane for gas separation. Sep Purif Technol. 2011; 81: 243-264.

[54] Shah R, Gale JD, Payne MC. Comparing the acidities of zeolites and SAPOs from first principles. Chem Commun. 1997; 1: 131-132.

[55] Hoek EM V, Ghosh AK, Huang X, et al. Physical-chemical properties, separation performance, and fouling resistance of mixed-matrix ultrafiltration membranes. Desalination. 2011; 283: 89-99.

[56]Han R, Zhang S, Liu C, et al. Effect of NaA zeolite particle addition on poly (phthalazinone ether sulfone ketone) composite ultrafiltration (UF) membrane performance. J Memb Sci. 2009; 345: 5-12.

[57] Li JF, Xu ZL, Yang H, et al. Effect of $\mathrm{TiO}_{2}$ nanoparticles on the surface morphology and performance of microporous PES membrane. Appl Surf Sci. 2009; 255: 4725-4732.

[58] Wang R., Li D. F., Liu M., et al. Impact of DEA solutions with and without $\mathrm{CO}_{2}$ loading on porous polypropylene membranes intended for use as contactors. Journal of Membrane Science. 2004; 229(1-2): 147-157.

[59] Atchariyawut S., Feng C., Wang R. Effect of membrane structure on mass-transfer in the membrane gas-liquid contacting process using micro porous PVDF hollow fibers. Journal of Membrane Science. 2006; 285: $272-281$.

[60] Khaisri S., Demontigny D. Comparing membrane resistance and absorption performance of three different membranes in a gas absorption membrane contactor. Separation and Purification Technology. 2009; 65: 290-297.

[61] Saeid Rajabzadeh, Shinya Yoshimoto, Masaaki Teramoto, et al. $\mathrm{CO}_{2}$ absorption by using PVDF hollow fiber membrane contactors with various membrane structures. Separation and Purification Technology. 2009; 69: $210-220$.

[62] Sayed A. M. Marzouk, Mohamed H. Al-Marzouqi, Nadia Abdullatif, et al. Removal of percentile level of $\mathrm{H}_{2} \mathrm{~S}$ from pressurized $\mathrm{H}_{2} \mathrm{~S}-\mathrm{CH}_{4}$ gas mixture using hollow fiber membrane contactors and absorption solvents. Journal of Membrane Science. 2010; 351: 21-27.

[63] Yuexia Lv, Xinhai Yu, Shan-Tung Tu, et al. Experimental studies on simultaneous removal of $\mathrm{CO}_{2}$ and $\mathrm{SO}_{2}$ in a polypropylene hollow fiber membrane contactor. Applied Energy. 2012; 97: 283-288. 
[64] N. Ghasem, M. Al-marzouqi, N. A. Rahim. Preparation and properties of polyethersulfone hollow fiber membranes with o-xylene as an additive used in membrane contactors for $\mathrm{CO}_{2}$ absorption. Sep. Purif. Technol. 2012; 99: 91-103.

[65] S. Rajabzadeh, S. Yoshimoto, M. Teramoto, et al. Effect of membrane structure on gas absorption performance and long-term stability of membrane contactors. Sep. Purif. Technol. 2013; 108: 65-73.

[66] M. Sadoogh, A. Mansourizadeh, H. Mohammadinik. An experimental study on the stability of PVDF hollow fiber membrane contactors for $\mathrm{CO}_{2}$ absorption with alkanolamine solutions. RSC Adv. 2015; 5: 86031-86040. 